\title{
Inhibitory effect of dexamethasone on residual Lewis lung cancer cells in mice following palliative surgery
}

\author{
NINGBO SUN ${ }^{1}$, HUAIJUN JI ${ }^{2}$, WEI WANG ${ }^{3}$, QIANG ZHU ${ }^{3}$, MING CAO $^{3}$ and QI ZANG ${ }^{3}$ \\ ${ }^{1}$ Department of Cardiac Surgery, Shengli Oilfield Central Hospital, Dongying, Shandong 257034; \\ ${ }^{2}$ Surgery Division, Graduate Department, Weifang Medical College, Weifang, Shandong 261031; \\ ${ }^{3}$ Department of Thoracic Surgery, Qianfoshan Hospital Affiliated to Shandong University, Jinan, Shandong 250014, P.R. China
}

Received July 2, 2015; Accepted September 30, 2016

DOI: $10.3892 / 01.2016 .5422$

\begin{abstract}
Previous studies found that glucocorticoids were closely associated with the oncogenesis and development of numerous types of tumors. The aim of the present study was to investigate the effect of dexamethasone on the growth and angiogenesis of Lewis lung cancer cells in mice who received palliative surgery. Lewis lung carcinoma cells were inoculated subcutaneously into the right axilla of C57BL/6 mice. When tumor diameter reached $0.5 \mathrm{~cm}, 2$ weeks later, palliative surgery was performed, and the mice were randomly divided into 3 groups with 6 animals in each group (control group, cisplatin group and dexamethasone group). From the first postoperative day, all the mice were administered with saline, cisplatin or dexamethasone for 10 days, and changes in xenograft tumor volumes were monitored. Cisplatin and dexamethasone were dissolved in normal saline $(0.9 \%)$. All mice were sacrificed on postoperative day 11, and the whole body and the local tumors were weighed immediately. The expression levels of hypoxia inducible factor $1 \alpha(\mathrm{HIF}-1 \alpha)$, vascular endothelial growth factor (VEGF), proliferating cell nuclear antigen and the microvessel density (MVD) in the tumor mass, were measured by immunohistochemistry, western blotting and quantitative polymerase chain reaction. In the present study, tumor growth was inhibited in the cisplatin group and dexamethasone group, and the weights of tumors were significantly decreased in the cisplatin group and dexamethasone group compared with the control group $(\mathrm{P}<0.001)$. The expression levels of HIF-1 $\alpha$ and VEGF and the MVD were significantly lower in the cisplatin group and dexamethasone group than in the control group $(\mathrm{P}<0.01)$. In conclusion, dexamethasone can inhibit the growth and angiogenesis of residual Lewis lung carcinoma subsequent
\end{abstract}

Correspondence to: Professor Qi Zang, Department of Thoracic Surgery, Qianfoshan Hospital Affiliated to Shandong University, 16766 Jingshi Road, Jinan, Shandong 250014, P.R. China

E-mail: qzang2005@sina.com

Key words: dexamethasone, residual lung carcinoma, palliative surgery, anti-angiogenesis, HIF-1 $\alpha$, VEGF, PCNA, MVD to palliative surgery partially through downregulation of HIF- $1 \alpha$ and VEGF signaling pathways.

\section{Introduction}

The level of morbidity and mortality in lung cancer is among the highest of all cancers in the world (1). Therefore, lung cancer poses a serious threat to human health, so it is important to conduct research regarding the possible mechanisms of the development and metastasis of lung cancer in order to improve the treatment of this disease. Glucocorticoids, which are secreted by the adrenal glands, are steroid hormones that can regulate the growth, development and differentiation of the organism and stabilize the internal environment. For almost all cells glucocorticoids play a regulatory role in growth and differentiation. Dexamethasone is a synthetic glucocorticoid that is widely used clinically in order to improve the general condition of cancer patients and reduce adverse reactions to chemotherapy (2). Previous studies have found that dexamethasone may inhibit the expression of vascular endothelial growth factor (VEGF) mRNA in induced rat glioma cells (3) and human vascular smooth muscle cells (4) in vitro. It has been suggested that dexamethasone has certain anti-angiogenic and anti-tumor effects $(5,6)$. In addition, dexamethasone may also inhibit proliferation and induce differentiation in numerous tissue-derived carcinoma cells, such as gynecological and digestive system tumor cells (7-9). However, little research has been performed on the inhibitory effect of dexamethasone on lung carcinoma cells, particularly for patients who received palliative surgery.

The aim of the present study was to investigate the inhibitory effect of dexamethasone on angiogenesis, cell proliferation and tumor growth in residual Lewis lung cancer cells in mice subsequent to palliative surgery by establishing a C57BL/6 mouse xenograft model using Lewis lung carcinoma cells. The present study aims to expand current treatments of lung cancer and provide a new basis for hormone therapy for patients, particularly those who received palliative surgery.

\section{Materials and methods}

Animal models. The use of 18 male athymic BALB/c nude mice, weighing $20 \pm 6 \mathrm{~g}$ each, aged between 6 and 8 weeks, 
was approved by Animal Experiment Center of Shandong University (Jinan, China). This study was performed strictly in accordance with the recommendations in the Guide for the Care and use of Laboratory Animals of the National Institutes of Health. All experimental protocols described in the present study were approved by the Committee on Animal Investigation of Shandong Medical College of Shandong University (Jinan, China).

Materials. Lewis lung carcinoma cells were obtained from Shandong Academy of Medical Sciences (Jinan, China). Cisplatin was purchased from Qilu Pharmaceutical Co., Ltd., (Jinan, China) and was dissolved in $0.2 \mathrm{ml}$ normal saline to give a $2 \mathrm{mg} / \mathrm{ml}$ stock solution at $4^{\circ} \mathrm{C}$, mice in the cisplatin treatment group were administered $2 \mathrm{mg} / \mathrm{kg}$ cisplatin. Bicinchoninic acid (BCA) protein assay kit was obtained from Pierce Biotechnology, Inc., (Rockford, IL, USA). Polyvinylidene difluoride (PVDF) membranes were from Pall Life Sciences (EMD Millipore, Billerica, MA, USA). Rabbit monoclonal anti-human hypoxia inducible factor $1 \alpha$ (HIF-1 $\alpha$ ) antibody (cat. no. ab51608), rabbit polyclonal anti-cluster of differentiation 31 (CD31) antibody (cat. no. ab28364), rabbit monoclonal anti-human VEGF antibody (cat. no. ab32562) and rabbit polyclonal anti-human proliferating cell nuclear antigen (PCNA) antibody (cat. no. ab29) were purchased from Abcam (Cambridge, UK).

Animal groups and processing. Lewis lung carcinoma cells (Shandong Academy of Medical Sciences) were cultivated in plastic tissue culture flasks (Corning Incorporated, Corning, NY, USA) with complete Dulbecco's modified Eagle's medium-F12 (Gibco; Thermo Fisher Scientific, Inc., Waltham, MA, USA) containing 10\% fetal bovine serum (Gibco; Thermo Fisher Scientific, Inc.) and $1 \%$ penicillin-streptomycin (HyClone; GE Healthcare Life Sciences, Logan, UT, USA). The cells were then placed in a $37^{\circ} \mathrm{C}$ culture incubator with a $5 \% \mathrm{CO}_{2}$ atmosphere. The cell suspension was collected, which contained logarithmic growth phase cells, and the cell density was adjusted to $1 \times 10^{7}$ cells $/ \mathrm{ml}$ with phosphate-buffered saline. A $0.2 \mathrm{ml}$ suspension containing $2 \times 10^{6}$ cells was inoculated into the right axilla of each mouse, and they were then fed under a specific pathogen-free environment.

The tumors of mice were observed as subcutaneous nodules in the right axilla, 7 days following inoculation. The rate of tumor formation in mice was $100 \%$. When the tumor diameter reached $0.5 \mathrm{~cm}, 2$ weeks later, palliative surgery was performed leaving $\sim 1 \mathrm{~mm}^{3}$ tumor tissue in the right axilla of the mice. The mice were then divided equally into 3 groups at random (control group; cisplatin group; and dexamethasone group). Postoperatively, all the mice were administered with different treatments for 10 consecutive days. The mice of the control group were intraperitoneally administered with saline. The cisplatin group was intraperitoneally administered with $2 \mathrm{mg} / \mathrm{kg}$ cisplatin dissolved in $0.2 \mathrm{ml}$ saline on days 1,2 and 3, and $0.2 \mathrm{ml}$ saline alone was administered on the other days. The mice of the second group were intraperitoneally administered with $5 \mathrm{mg} / \mathrm{kg}$ dexamethasone (Shandong Xinhua Pharmaceutical Co., Ltd., Shandong, China) dissolved in $0.2 \mathrm{ml}$ saline once each day. Each group received treatment for 10 consecutive days. During the period of treatment subsequent to palliative surgery, the mental state, eating habits, activities and defecation of the mice were observed. The subcutaneous tumor nodules of each mouse were measured on days 4, 5, 6, 7, 8, 9 and 10 post-surgery using vernier calipers (accuracy of $0.1 \mathrm{~mm}$ ) and calculated the volume of the tumors as follows: $\mathrm{V}\left(\mathrm{mm}^{3}\right)=0.52 \mathrm{ab}^{2}$ (a, longest diameter of the nodule; $b$, shortest diameter). The average of each group was used to plot the tumor growth curve. All mice were sacrificed on day 11 postoperatively; the whole body and the local tumors were weighed immediately. The inhibitory rate of the tumor was calculated as follows: Inhibitory rate (IR) $(\%)=[$ control group average tumor weight $(\mathrm{g})$ - treatment group average tumor weight $(\mathrm{g})]$ / control group average tumor weight (g) $x$ 100. The tumors were put in $4 \%$ paraformaldehyde for IHC immediately. Portions of each tumor were immediately put in liquid nitrogen and stored at $-80^{\circ} \mathrm{C}$ for RT-quantitative polymerase chain reaction (RT-PCR) and western blotting.

IHC. Antibodies against HIF-1 $\alpha$, VEGF and PCNA were used for IHC analysis of tumors, which was performed according to the manufacturer's protocol. Results may be judged according to the staining intensity of positive cells and the percentage of positive cells. Each $3-\mu$ m-thick section was observed by microscopy, with 10 random high-power field measurements taken at a x200 magnification. A reference method of scoring was used as previously described by Mamori et al (10). The staining intensity was scored as follows: No staining, 0 ; slight staining, 1; moderate staining, 2; and deep staining, 3. The criteria for scoring the percentage of positive cells was as follows: No positive cells, 0 ; $<25 \%$ positive cells, $1 ; 25-50 \%$ positive cells, 2 ; and $>50 \%$ positive cells, 3 . The 2 scores were then added and the judgment standard of results was as follows: Strong positive (++), 9-12; positive (+), 5-8; and negative (-), 0-4. Assessment of vascularity used the average of the microvessel density (MVD), which was judged by assessing IHC staining for CD31 as reported by Vermeulen et al (11). The slice was scanned to identify the most intense vascularization areas under a microscope at a low magnification (x100). Subsequently, these areas were counted by observing the slice at a $\mathrm{x} 400$ magnification in 10 chosen fields of view. A single cluster of endothelial cells or a branch structure of vascular stem cells that were stained positive for CD31 were regarded as one blood vessel. The average vessel number of MVD in 10 randomly assigned fields was considered to be the number of microvessels for each case.

RNA isolation and RT-qPCR assay. RT-qPCR was utilized for HIF-1 $\alpha$, VEGF and PCNA expression analysis. Total RNA was isolated from tumor tissue using the RNA simple total RNA kit (Tiangen Biotech Co., Ltd., Beijing, China), according to the manufacturer's protocol. The concentration of total RNA was detected by spectrophotometry (SPECTRA MAX190; Molecular Devices, LLC, Sunnyvale, CA, USA). Complementary DNA (cDNA) was synthesized from $2 \mu \mathrm{g}$ total RNA using the fastquant RT kit (Tiangen Biotech Co., Ltd.), according to the manufacturer's protocol. qPCR was performed in an ABI ViiA7 Dx instrument (Thermo Fisher Scientific, Ltd., Waltham, MA, USA) using the SYBR green PCR Master Mix (Tiangen Biotech Co., Ltd.) following the manufacturer's protocol. Rat $\beta$-actin gene was used as the control. Gene-specific primers were designed in GenBank (Accession number, NM_02306; National Center for Biotechnology Information, Bethesda, MD, USA) Primer sequences for HIF-1 $\alpha$, VEGF, PCNA and $\beta$-actin 
are described as follows: HIF-1 $\alpha$ forward, 5'-TGTGTTTGATTT TACTCATCCATGT-3' and, reverse, 5'-CTCCGCTGTGTG TTTAGTTCTT-3'; VEGF forward, 5'-AAAGGGAAAGGG TCAAAAACGAA-3' and reverse, 5'-AGGAACATTTACACG TCTGCGG-3'; PCNA forward, 5'-ATCGTGAATCGGGGG ACCTTG-3' and reverse, 5'-CTTTGAGAGCCTCCAGCACCT TC-3'; $\beta$-actin forward, 5'-GACCACACCTTCTACAATGAG-3' and reverse, 5'-GCATACCCCTCGTAGATGGG-3'.

PCR results were quantified using the $\triangle \mathrm{Cq}$ method following the formula: Ratio $=2-\Delta \mathrm{Cq}$, where $\Delta \mathrm{Cq}=\mathrm{Cq}$ target gene $-\mathrm{Cq}$ endogenous control gene ( $\beta$-actin) (12).

Western blotting. The expression of HIF-1 $\alpha$, VEGF and PCNA was determined by western blot analysis. Tumor tissue was lysed in lysis buffer (Sigma-Aldrich; Merck Millipore, Darmstadt, Germany) and centrifuged at $12,000 \times \mathrm{g}$ for $30 \mathrm{~min}$ at $4^{\circ} \mathrm{C}$. The supernatant was collected following centrifugation. The protein concentration was determined using a BCA protein assay kit (Pierce Biotechnology, Inc.). The samples were boiled, sheared and clarified by centrifugation. Equal quantities $(20 \mu \mathrm{g})$ of protein were loaded onto and separated by $10 \%$ sodium dodecyl sulfate-polyacrylamide gel electrophoresis and transferred to a PVDF membrane (EMD Millipore). The membranes were blocked with 5\% skim milk in Tris-buffered saline and Tween-20 (TBST) buffer for $1.5 \mathrm{~h}$ with agitation, and the membranes were incubated with primary antibodies against HIF-1 $\alpha$ (dilution, 1:1,000), VEGF (dilution, 1:800) and PCNA (dilution, 1:1,000) overnight at $4^{\circ} \mathrm{C}$. The membranes were subsequently rinsed 3 times with TBST and incubated with polyclonal sheep anti-rat IgG conjugated to horseradish peroxidase (dilution, 1:1,000; Sigma-Aldrich; Merck Millipore; cat. no. BA1050). The visualization of immunosignals was performed using the protein detector 5-bromo-4-chloro-3-indolyl-phosphate/nitro blue tetrazolium western blotting kit (Beyotime Institute of Biotechnology, Haimen, China) was in accordance with the manufacturer's protocol. ECL (EMD Millipore) images were captured with a FluorChem E instrument (Cell Biosciences, Inc., Santa Clara, CA, USA). The present study used ImageQuant 5.2 software (GE Healthcare, Little Chalfont, UK) to conduct the quantification of each sample. A separate membrane was prepared using the same methods, and was probed with mouse polyclonal anti-human GAPDH (dilution, 1:1,000; cat. no. ab8245; Abcam) antibodies.

Statistical analysis. The data was analyzed using the SPSS 13.0 statistical software (SPSS, Inc., Chicago, IL, USA). Values are expressed as the mean \pm standard error of the mean. Significance was tested by one-way analysis of variance with Dunnett's test. $\mathrm{P}<0.05$ was considered to indicate a statistically significant difference. The association between HIF-1 $\alpha$ and VEGF expression and MVD was analyzed using Spearman's rank correlation coefficient. $\mathrm{P}<0.05$ was considered to indicate a statistically significant difference.

\section{Results}

Effects of dexamethasone on residual Lewis lung cancer cells growth subsequent to palliative resection surgery. Tumors in the normal saline group grew significantly faster than those in the other groups. The growth curve (Fig. 1) showed tumor growth in the treated groups gradually slowed down. Compared to controls, treatments with $2 \mathrm{mg} / \mathrm{kg}$ cisplatin, and $5 \mathrm{mg} / \mathrm{kg}$ dexamethasone were found to apparently inhibit the tumor growth, and the inhibitory rate was 39.4 and $72.24 \%$, respectively (Table I). The inhibitory effect was evident in the dexamethasone groups and the cisplatin groups $(\mathrm{P}<0.001)$ compared with the control group. The mice in dexamethasone groups and the cisplatin groups were in good condition and increased in body weight following the experiment (Table I). This suggests that dexamethasone not only inhibited the growth of residual Lewis lung cancer cells subsequent to palliative surgery, but also reduced the tumor's consumption of resources.

HIF-l $\alpha, V E G F, P C N A$ expression and MVD in tumors. VEGF was expressed in the cytoplasm or membrane of tumor cells based on IHC staining of tumors. HIF-1 $\alpha$ and PCNA protein showed mainly positive staining in the nucleus of tumor cells. VEGF protein showed positive staining mainly in the cytoplasm of the tumor cells. Positive staining of HIF-1 $\alpha$, VEGF and PCNA was characterized by brown and finely granular staining at the original x400 magnification in tumors (Fig. 2A-I). Cells positive for CD31 were stained brown in the cytoplasm. Microvessel distribution is shown at the original $\times 400$ magnification (Fig. 2J-L). In the present results, the expression of HIF-1 $\alpha$, VEGF and PCNA in the normal saline group was higher than that in the other treatment groups. Grayscale intensity variants of HIF-1 $\alpha$, VEGF immunoreactivity were assessed by Image-Pro Plus software (Media Cybernetics, Inc., Rockville, MD, USA). Compared with the control groups, HIF-1 $\alpha$ ( $\mathrm{P}=0.0013)$, VEGF $(\mathrm{P}=0.0025)$ and $\mathrm{PCNA}(\mathrm{P}=0.0038)$ expression scores, and MVD counts $(\mathrm{P}=0.0018)$, decreased significantly in the cisplatin and dexamethasone groups. In each comparison, there was a significant difference (Table II).

Expression levels of HIF-1 $\alpha, V E G F$ and PCNA mRNA in the control, cisplatin and dexamethasone groups were quantified by $q P C R$. HIF-1 $\alpha$, VEGF and PCNA mRNA were quantified in the control, cisplatin and dexamethasone groups by qPCR. As shown in Fig. 3, the expression levels of HIF-1 $\alpha$ ( $\mathrm{P}=0.018)$, VEGF ( $\mathrm{P}=0.012)$ and PCNA ( $\mathrm{P}=0.0018)$ mRNA in the dexamethasone group were significantly reduced compared with the control group, which suggests that dexamethasone can inhibit the expression levels of HIF-1 $\alpha$, VEGF and PCNA mRNA. The results indirectly suggest that dexamethasone may inhibit angiogenesis.

Effect of dexamethasone treatment on HIF-1 $\alpha, V E G F$ and PCNA protein expression as assessed by western blot analysis. HIF-1 $\alpha$, VEGF and PCNA expression was normalized to glyceraldehyde 3-phosphate dehydrogenase expression by band intensity (Fig. 4). Band intensities were analyzed by ImageJ software (National Institutes of Health, Bethesda, MD, USA). As shown in Fig. 5, HIF-1 $\alpha(\mathrm{P}=0.007)$, VEGF $(\mathrm{P}=0.019)$ and PCNA ( $\mathrm{P}=0.0094)$ expression decreased significantly in the tissue treated with dexamethasone.

\section{Discussion}

Tumors cannot grow beyond $0.2 \mathrm{~mm}$ from vessels, suggesting that angiogenesis is necessary for the progression and metastasis 
Table I. Body weight, tumor size and tumor IR of the residual Lewis lung cancer cells in the 3 groups.

\begin{tabular}{|c|c|c|c|c|}
\hline \multirow[b]{2}{*}{ Group } & \multicolumn{2}{|c|}{ Body weight, g } & \multirow[b]{2}{*}{ Tumor weight, $\mathrm{g}$} & \multirow[b]{2}{*}{$\mathrm{IR}, \%$} \\
\hline & Prior to treatment & Subsequent to treatment & & \\
\hline Normal saline & $22.44 \pm 0.24$ & $24.57 \pm 0.18$ & $0.66 \pm 0.08$ & \\
\hline Dexamethasone & $22.72 \pm 0.28$ & $24.92 \pm 0.14$ & $0.40 \pm 0.06^{\mathrm{a}}$ & 39.4 \\
\hline Cisplatin & $22.54 \pm 0.25$ & $25.49 \pm 0.17$ & $0.17 \pm 0.05^{\mathrm{a}, \mathrm{b}}$ & 72.24 \\
\hline
\end{tabular}

Data are expressed as the mean \pm standard error of the mean. ${ }^{a} \mathrm{P}<0.01$ vs. normal saline group; ${ }^{\mathrm{b}} \mathrm{P}<0.01$ vs. dexamethasone group. IR, inhibition rate.

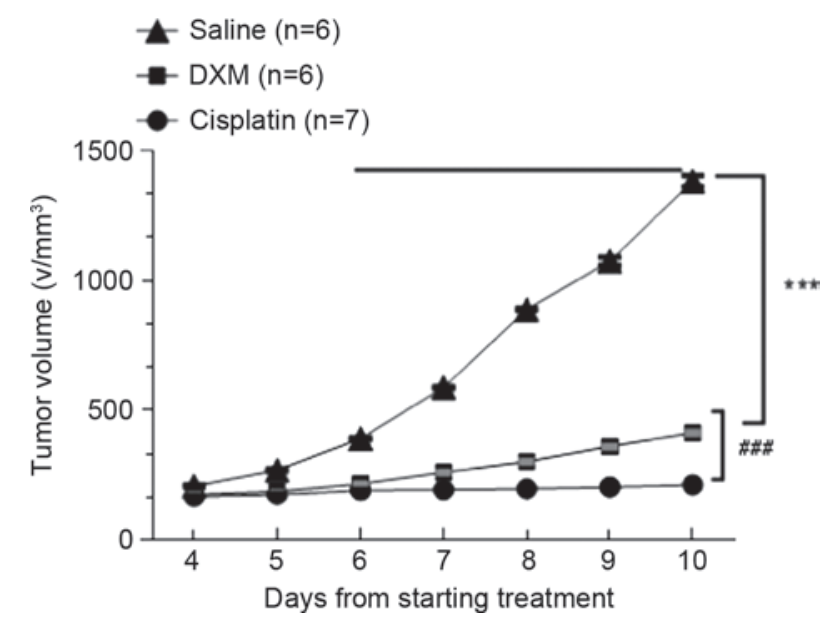

Figure 1. Tumor growth curve demonstrating significantly decreased tumor growth in the treatment groups. ${ }^{* * *} \mathrm{P}<0.001$, dexamethasone group vs. normal saline group; ${ }^{\# \#} \mathrm{P}<0.01$, cisplatin group vs. dexamethasone group. DXM, dexamethasone.

of tumors (13). Numerous malignant tumors, including lung cancers, overexpress angiogenic factors (14). HIF-1 $\alpha$ is one major regulator of the neovascularization process. HIF-1 $\alpha$ was first identified by Wang and Semenza in 1992 (15) when they studied hypoxia-inducible gene expression. HIF-1 $\alpha$ is the most important factor associated with cell responses under hypoxic conditions for cell survival and angiogenesis (16). HIF-1 $\alpha$ activates the transcription of numerous genes by binding to the hypoxia response element (HRE) in the promoter, such as VEGF, and it plays an important role in the angiogenesis, survival, invasion and metastasis of tumors. In the process of tumor formation and development, VEGF, which has a variety of functions, is the major factor for inducing angiogenesis. VEGF plays an important role in mitogenic and chemotactic properties of vascular endothelial cells, and stimulates the endothelial cell proliferation for increasing vascular permeability and promoting angiogenesis by integrating with insulin-specific receptors (17). Excessive expression of the VEGF gene promotes angiogenesis and tumor growth, and leads to unlimited amplification of the tumor vasculature. In addition, VEGF accelerates the invasion and transfer of tumors through autocrine invasion. The process of angiogenesis is tightly regulated by a series of protein and anti-angiogenic molecules in normal physiology $(18,19)$. In addition, HIF-1 $\alpha$ and VEGF are the most important factors of angiogenesis. They facilitate the development of malignant cells by increasing vascular permeability (20-23). The excessive expression of HIF-1 $\alpha$ and VEGF is closely associated with the progression and angiogenesis of the tumor. Previous studies demonstrated that hypoxia leads to overexpression of VEGF, which promotes angiogenesis through HIF-1 $\alpha$ in the development of the tumor in vivo $(24,25)$. The unlimited proliferation of mesenchymal cells is regulated by tumor cells through an intercellular signaling system, leading to the tumor microenvironment that promotes the proliferation and development of tumor cells. In general, the microenvironment of the tumor appears to be associated with extremely vigorous tumor angiogenesis (26). Malignant tumor growth and metastasis depends on angiogenesis, the extent of which determines the tumor microenvironment and thus the degree of tumor metastasis.

At present, accumulating evidence has already demonstrated that HIF-1 $\alpha$ and VEGF play an important role in promoting angiogenesis, which is well recognized as a pivotal step for cancer growth, invasion and metastasis in solid tumors (27). Proliferation signals from outside of the cell are involved in PCNA in order to promote DNA synthesis (28), so that PCNA can mediate cell survival and proliferation. Studies have confirmed that PCNA protein synthesis may indirectly reflect the rate of DNA synthesis and cell proliferation during the cell cycle. As a result, during the development of tumors, PCNA is a reliable factor of the proliferative phase, providing a marker for the proliferation of tumor cells (29). Lung cancer is rich in blood vessels, and previous research (30) has identified excessive expression of HIF-1 $\alpha$ and VEGF in patients. Therefore, a method of therapy that inhibits angiogenesis may be identified as one of the most promising and hopeful strategies to restrain the development of lung cancer and prolong the lives of patients who receive palliative surgery. Therefore, theoretically, tumor treatments may consist of not only cytotoxic agents against tumor cells, but also agents targeted to inhibit the proliferation of or kill interstitial cells, such as vascular endothelial cells, which play a critical role in tumor growth.

The study by Folkman (31) demonstrated that the inhibition of tumor angiogenesis is able to slow down the development of tumors or reduce tumor size and burden. The importance of angiogenesis to tumor formation and development is gradually being recognized (32).

In order to demonstrate how dexamethasone inhibited the overexpression of VEGF in remaining tumor cells subsequent to palliative surgery, the present study divided subjects into 3 groups (cisplatin, dexamethasone and normal saline groups) to 
Table II. Expression scores of HIF-1 $\alpha$, VEGF, PCNA and MVD in each group.

\begin{tabular}{lccccc}
\hline Group & Cases, $\mathrm{n}$ & HIF-1 $\alpha$ score & VEGF score & PCNN score & MVD score \\
\hline Normal saline & 6 & $4.21 \pm 0.35$ & $4.47 \pm 0.34$ & $4.76 \pm 0.31$ & $29.75 \pm 5.64$ \\
Dexamethasone & 6 & $2.67 \pm 0.43^{\mathrm{a}}$ & $2.74 \pm 0.35^{\mathrm{a}}$ & $2.91 \pm 0.24^{\mathrm{a}}$ & $17.01 \pm 3.24^{\mathrm{a}}$ \\
Cisplatin & 6 & $1.39 \pm 0.25^{\mathrm{a}, \mathrm{b}}$ & $1.60 \pm 2.35^{\mathrm{a}, \mathrm{b}}$ & $1.67 \pm 0.43^{\mathrm{a}, \mathrm{b}}$ & $12.09 \pm 2.96^{\mathrm{a}, \mathrm{b}}$ \\
\hline
\end{tabular}

${ }^{a} \mathrm{P}<0.01$ vs. normal saline group; ${ }^{\mathrm{b}} \mathrm{P}<0.01$ vs. dexamethasone group. HIF-1 $\alpha$, hypoxia inducible factor $1 \alpha$; VEGF, vascular endothelial growth factor; PCNA, proliferating cell nuclear antigen; MVD, microvessel density.
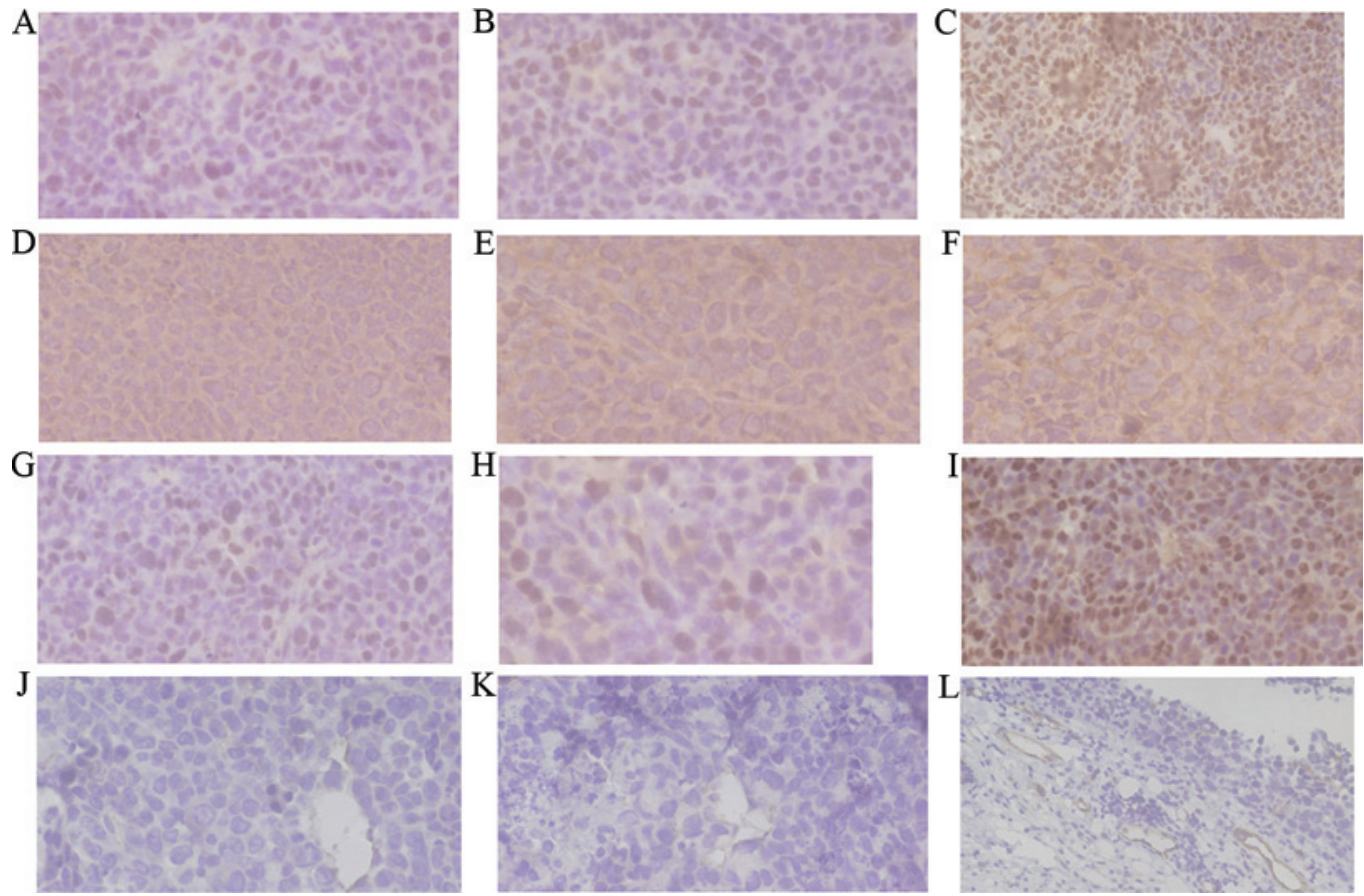

Figure 2. HIF-1 $\alpha$, VEGF, PCNA and MVD staining decreased significantly in the cisplatin and dexamethasone groups. (A) HIF-1 $\alpha$ staining in the cisplatin group. (B) HIF-1 $\alpha$ staining in the dexamethasone group. (C) HIF-1 $\alpha$ staining in the normal saline group. (D) VEGF staining in the cisplatin group. (E) VEGF staining in the dexamethasone group. (F) VEGF staining in the normal saline group. (G) PCNA staining in the cisplatin group. (H) PCNA staining in the dexamethasone group. (I) PCNA staining in the normal saline group. (J) MVD staining in the cisplatin group. (K) MVD staining in the dexamethasone group. (L) MVD staining in the normal saline group. The representative images were captured at a magnification of x 400 . HIF-1 $\alpha$, hypoxia inducible factor $1 \alpha$; VEGF, vascular endothelial growth factor; PCNA, proliferating cell nuclear antigen; MVD, microvessel density.

analyze the expression of associated proteins, such as HIF-1 $\alpha$, VEGF and PCNA by IHC, western blotting and RT-qPCR. The present study showed that the protein expression of HIF-1 $\alpha$, VEGF and PCNA in tumor tissues of the dexamethasone group, was significantly lower than those in the control group.

However, MVD is also an important factor of angiogenesis. Tumor angiogenesis was evaluated by microvessel density (MVD). Tumor immunostaining for CD31 in endothelial cells was performed to detect MVD. It was found that MVD in the tumor tissues of the dexamethasone group was also significantly lower than those in the control tumor tissues. The decreased expression of HIF-1 $\alpha$, VEGF and PCNA in the present study suggested that dexamethasone had an inhibitory effect on angiogenesis, which was in accordance with previous experimental results that tumor progression and metastasis can be inhibited by various antiangiogenic therapies $(33,34)$. The present results show that tumor growth was significantly inhibited in mice receiving dexamethasone. Not only was

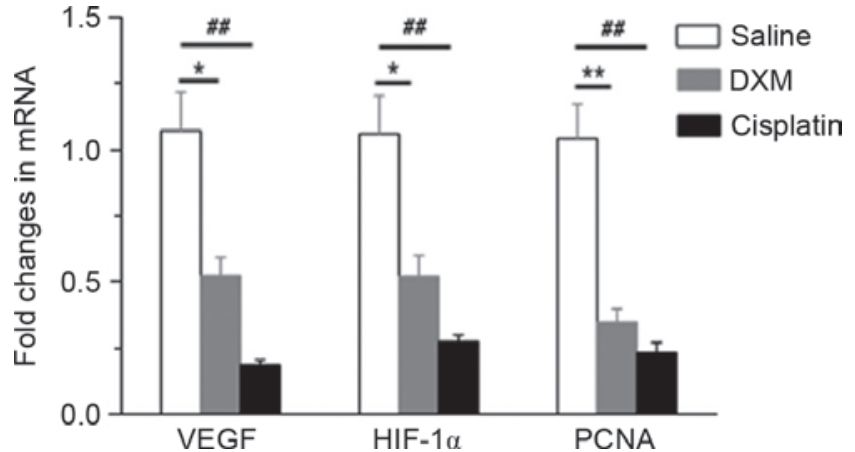

Figure 3. Reverse transcription-quantitative polymerase chain reaction analysis of VEGF, HIF-1 $\alpha$ and PCNA mRNA levels in the control, dexamethasone and cisplatin groups. Values are expressed as the mean \pm standard error of the mean. Significance was tested by one-way analysis of variance with Dunnett's test. $P<0.05$ was considered to indicate a statistically significant difference. ${ }^{*} \mathrm{P}<0.05,{ }^{* * *} \mathrm{P}<0.01$, dexamethasone group vs. normal saline group; ${ }^{\# \#} \mathrm{P}<0.01$, cisplatin group vs. normal saline group. VEGF, vascular endothelial growth factor; HIF-1 $\alpha$, hypoxia inducible factor $1 \alpha$; PCNA, proliferating cell nuclear antigen; DXM, dexamethasone. 


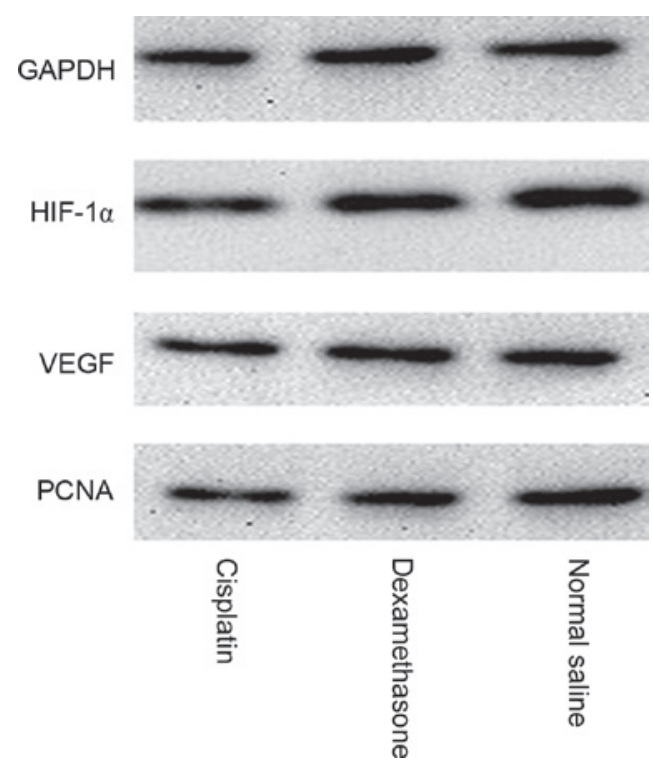

Figure 4. Western blot analysis of HIF-1 $\alpha$, VEGF and PCNA protein expression in tumors. Lane 1, cisplatin group; lane 2, dexamethasone group; lane 3 , normal saline group. GAPDH, glyceraldehyde 3-phosphate dehydrogenase HIF-1 $\alpha$, hypoxia inducible factor $1 \alpha$; VEGF, vascular endothelial growth factor; PCNA, proliferating cell nuclear antigen; DXM, dexamethasone.
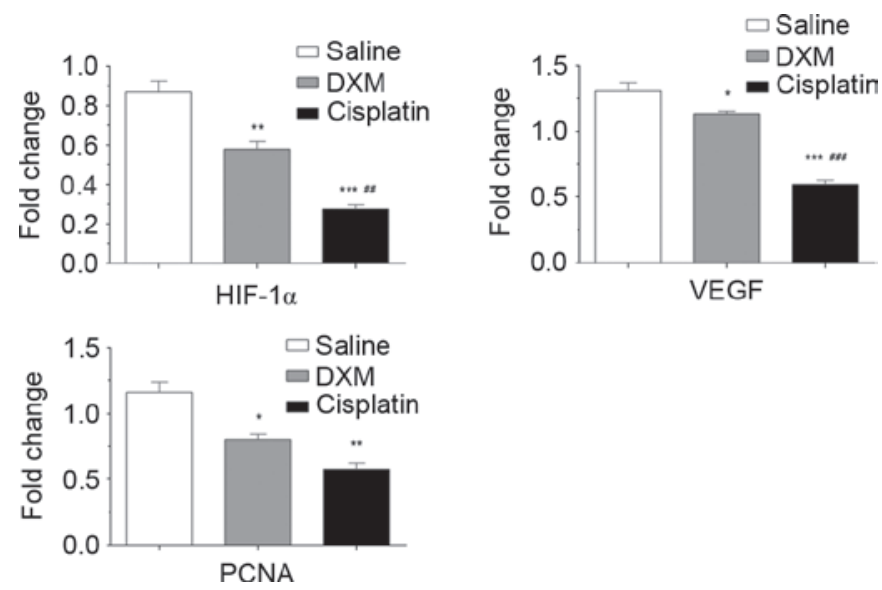

Figure 5. Western blot analysis of HIF-1 $\alpha$, VEGF and PCNA protein expression in the control group, dexamethasone group, and cisplatin group. Protein expression was significantly decreased in the cisplatin and dexamethasone treatment groups. Values are expressed as the mean \pm standard error of the mean. Significance was tested by one-way analysis of variance with Dunnett's test. $\mathrm{P}<0.05$ was considered to indicate a statistically significant difference. ${ }^{*} \mathrm{P}<0.05,{ }^{* * *} \mathrm{P}<0.01,{ }^{* * *} \mathrm{P}<0.001$ vs. normal saline group; ${ }^{\# \#} \mathrm{P}<0.01,{ }^{\# \#} \mathrm{P}<0.01$ vs. dexamethasone group. HIF-1 $\alpha$, hypoxia inducible factor $1 \alpha$; VEGF, vascular endothelial growth factor; PCNA, proliferating cell nuclear antigen; DXM, dexamethasone.

tumor growth significantly inhibited in the dexamethasone group, the MVD of tumor tissue in this group was also significantly lower than that in the control group. Expression levels of HIF-1 $\alpha$ and VEGF were lower than those in the control group, and the expression of the two markers showed a significant positive correlation (35-37). Therefore, dexamethasone indirectly inhibits the generation of angiogenic factors, such as VEGF, by decreasing the expression of HIF-1 $\alpha$, thereby inhibiting tumor angiogenesis. This is an important role of dexamethasone in anti-angiogenic effects and suppression of tumor growth. PCNA, a cofactor for the DNA polymerase $\delta$, is a type of nucleoprotein that is necessary for DNA synthesis within the nucleus. The present results suggested that dexamethasone significantly reduced PCNA expression.

In summary, dexamethasone can effectively inhibit the growth and angiogenic properties of residual Lewis lung carcinoma subsequent to palliative surgery in mice and also can reduce the adverse reaction to chemotherapy. Dexamethasone can serve as the basis for tumor hormone therapy, which provides a new method of postoperative adjuvant therapy for patients, particularly those who received palliative surgery.

\section{References}

1. Reck M, Heigener DF, Mok T, Soria JC and Rabe KF: Management of non-small-cell lung cancer: Recent developments. Lancet 382: 709-719, 2013.

2. Barnes PJ: Anti-inflammatory actions of glucocorticoids: Molecular mechanisms. Clin Sci 94: 557-572, 1998.

3. Machein MR, Kullmer J, Ronicke V, Machein U, Krieg M, Damert A, Breier G, Risau W and Plate KH: Differential downregulation of vascular endothelial growth factor by dexamethasone in normoxic and hypoxic rat glioma cells. Neuropathol Appl Neurobiol 25: 104-112, 1999.

4. Nauck M, Karakiulakis G, Perruchoud AP, Papakonstantinou E and Roth M: Corticosteroids inhibit the expression of the vascular endothelial growth factor gene in human vascular smooth muscle cells. Eur J Pharmacol 341: 309-315, 1998.

5. Rutz HP: Effects of corticosteroid use on treatment of solid tumours. Lancet 360: 1969-1970, 2002.

6. Wang H, Wang Y, Rayburn ER, Hill DL, Rinehart JJ and Zhang R: Dexcamethasone as a chemosensitizer for breast cancer chemotherapy: Potentiation of the antitumor activity of adriamycin, modulation of cytokine expression, and pharmacokinetics. Int J Oncol 30: 947-953, 2007.

7. Arafa HM, Abdel-Hamid MA, El-Khouly AA, Elmazar MM and Osman AM: Enhancement by dexamethasone of the therapeutic benefits of cisplatin via regulation of tumor angiogenesis and cell cycle kinetics in a murine tumor paradigm. Toxicology 222: 103-113, 2006.

8. Yemelyanov A, Czwornog J, Gera L, Joshi S, Chatterton RT Jr and Budunova I: Novel steroid receptor phyto-modulator compound a inhibits growth and survival of prostate cancer cells. Cancer Res 68: 4763-4773, 2008.

9. Moghaddam SJ, Haghighi EN, Samiee S, Shahid N, Keramati AR, Dadgar S and Zali MR: Immunohistochemical analysis of p53, cyclinD1, RB1, c-fos and N-ras gene expression in hepatocellular carcinoma in Iran. World J Gastroenterol 13: 588-593, 2007.

10. Mamori S, Nagatsuma K, Matsuura T, Ohkawa K, Hano H, Fukunaga M, Matsushima M, Masui Y, Fushiya N, Onoda H, et al: Useful detection of CD147 (EMMPRIN) for pathological diagnosis of early hepatocellular carcinoma in needle biopsy samples. World J Gastroenterol 13: 2913-2917, 2007.

11. Vermeulen PB, Gasparini G, Fox SB, Toi M, Martin L, McCulloch P, Pezzella F, Viale G, Weidner N, Harris AL and Dirix LY: Quantification of angiogenesis in solid human tumours: An international consensus on the methodology and criteria of evaluation. Eur J Cancer 32A: 2474-2484, 1996

12. Pfaffl MW: A new mathematical model for relative quantification in real-time RT-PCR. Nucleic Acids Res 29: e45, 2001.

13. Folkman $\mathrm{J}$ : What is the evidence that tumors are angiogenesis dependent? J Natl Cancer Inst 82: 4-6, 1990.

14. Yano T, Tanikawa S, Fujie T, Masutani M and Horie T: Vascular endothelial growth factor expression and neovascularisation in non-small cell lung cancer. Eur J Cancer 36: 601-609, 2000.

15. Wang GL and Semenza GL: Characterization of hypoxia-inducible factor 1 and regulation of DNA binding activity by hypoxia. J Biol Chem 268: 21513-21518, 1993.

16. Ferenci P, Fried M,Labrecque D, Bruix J, Sherman M, Omata M, Heathcote J, Piratsivuth T, Kew M, Otegbayo JA, et al: Hepatocellular carcinoma (HCC): A global perspective. J Clin Gastroenterol 44: 239-245, 2010. 
17. Da MX, Wu XT, Wang J, Guo TK, Zhao ZG, Luo T, Zhang MM and Qian K: Expression of cyclooxygenase-2 and vascular endothelial growth factor-C correlates with lymphangiogenesis and lymphatic invasion in human gastric cancer. Arch Med Res 39: 92-99, 2008.

18. Martínez A: A new family of angiogenic factors. Cancer Lett 236: 157-163, 2006.

19. Jakob C, Sterz J, Zavrski I, Heider U, Kleeberg L, Fleissner C, Kaiser M and Sezer O: Angiogenesis in multiple myeloma. Eur J Cancer 42: 1581-1590, 2006.

20. Pang RW, Joh JW, Johnson PJ, Monden M, Pawlik TM and Poon RT: Biology of hepatocellular carcinoma. Ann SurgOncol 15: 962-971, 2008.

21. Barr MP, Bouchier-Hayes DJ and Harmey JJ: Vascular endothelial growth factor is an autocrine survival factor for breast tumour cells under hypoxia. Int J Oncol 32: 41-48, 2008.

22. Tzao C, Lee SC, Tung HJ, Hsu HS, Hsu WH, Sun GH, Yu CP, Jin JS and Cheng YL: Expression of hypoxia-inducible factor (HIF)-1alpha and vascular endothelial growth factor (VEGF)-D as outcome predictors in resected esophageal squamous cel carcinoma. Dis Markers 25: 141-148, 2008.

23. Lin C, McGough R, Aswad B, Block JA and Terek R: Hypoxia induces HIF-1alpha and VEGF expression in chondrosarcoma cells and chondrocytes. J Orthop Res 22: 1175-1181, 2004.

24. Kaelin WG Jr: How oxygen makes its presence felt. Genes Dev 16: 1441-1445, 2002.

25. Liu Y, Cox SR, Morita T and Kourembanas S: Hypoxia regulates vascular endothelial growth factor gene expression in endothelia cells. Identification of a 5' enhancer. Circ Res 77: 638-643, 1995.

26. Fukumura D and Jain RK: Tumor microvasculature and microenvironment: Targets for anti-angiogenesis and normalization. Microvasc Res 74: 72-84, 2007.

27. Liu S, Yu M, He Y, Xiao L, Wang F, Song C, Sun S, Ling C and $\mathrm{Xu} \mathrm{Z}$ : Melittin prevents liver cancer cell metastasis through inhibition of the Rac1-dependent pathway. Hepatology 47: 1964-1973, 2008.
28. Zhao Y, Li XJ, Sui X, Tang XJ, Qin H and Ren H: Expression and significance of PCNA and Caspase-3 in the tissue of lung cancer. Xi Bao Yu Fen ZiMian Yi XueZa Zhi 26: 154-156, 2010 (In Chinese).

29. Yang XH and Zou L: Dual functions of DNA replication forks in checkpoint signaling and PCNA ubiquitination. Cell Cycle 8: 191-194, 2009.

30. Shen H, Feng G, Cui J, Du Q, Qin Y, Cai J, Shen L and Zhu Y: Clinical implications of serum hypoxia inducible factor-lá and vascular endothelial growth factor inlung cancer. Tumori 101: 404-411, 2015.

31. Folkman J: Tumor angiogenesis: Therapeutic implications. N Engl J Med 285: 1182-1186, 1971.

32. Folkman J: Angiogenesis: An organizing principle for drug discovery? Nat Rev Drug Discov 6: 273-286, 2007.

33. Ng KT, Guo DY, Cheng Q, Geng W, Ling CC, Li CX, Liu XB, Ma YY, Lo CM, Poon RT, et al: A garlic derivative, S-allylcysteine (SAC), suppresses proliferation and metastasis of hepatocellular carcinoma. PLoS ONE 7: e31655, 2012.

34. Wang L, Tang ZY, Qin LX, Wu XF, Sun HC, Xue Q and Ye SL: High-dose and long-term therapy with interferon-alfa inhibits tumor growth and recurrence in nude mice bearing human hepatocellular carcinoma xenografts with high metastatic potential. Hepatology 32 : 43-48, 2000.

35. Bremnes RM, Camps C and Sirera R: Angiogenesis in non-small cell lung cancer: The prognostic impact of neoangiogenesis and the cytokines VEGF and bFGF in tumours and blood. Lung Cancer 51: 143-158, 2006.

36. Liao M, Wang H, Lin Z, Feng J and Zhu D: Vascular endothelial growth factor and other biological predictors related to the postoperative survival rate on non-small cell lung cancer. Lung Cancer 33: $125-132,2001$.

37. Ushijima C, Tsukamoto S, Yamazaki K, Yoshino I, Sugio K and Sugimachi K: High vascularity in the peripheral region of non-small cell lung cancer tissue is associated with tumor progression. Lung Cancer 34: 233-241, 2001. 